\title{
Symbols of Transformation: Preludes Analysis of a Schizophrenia (Summary of Volume 05, of Carl Gustav Jung Book)
}

\author{
Henrique Guilherme Scatolin \\ PUC-SP (Pontificate Catholic University of São Paulo), São Paulo, Brazil
}

The summary of this book aims to highlight the main points of this rich work that demarcates the rupture between Freud and Jung. If, on the side of psychoanalysis, we have the book Totem and Taboo, as a response to the questions of Jung, on the side of the newly founded analytical psychology, we have this milestone, the book The Symbols of Transformation, representing the rupture between these two geniuses.

For understanding it, nothing is better than a panorama of its main passages. I remind that Jung wrote three prefaces for this book, once the preparation and modifications within this stretched for nearly 40 years, throughout his life.

This book was written when Jung was 36 years old, time of his breakup with Freud. In 1911, Jung wrote it up to chapter V, entitled The Song of the Moth and from 1912, continued to the second complete part, concluding it. Therefore, this summary is based on the definitive edition of 1952, in which the terminology of the period psychoanalysis was abandoned, a time in which Jung starts using the very terms of "analytical psychology", such as the major archetypal manifestations - the anima-animus, shadow, and selves.

The first milestone of this book is the new understanding of libido, in which this would be a psychic energy directed rather than a manifestation of pure sexuality, questioning, thus, Freud's psychoanalytic theory and its individualistic model. On the other hand, he brings the role of myth. It would be through this that the patient would contact his past and the lives of his ancestors. At this point, he interweaves a differentiation between the individual consciousness and the individual unconscious, exemplifying that the consciousness would only be the blooming and the fruiting characteristic of the season, evolving from the perennial underground rhizome that would be the roots of the universal mother originating in the collective unconscious. Therefore, the entire empirical, clinical material in this book has its roots in the collective unconscious, being the mutable psyche, a fruit of its history on the march and in which religion comes to play a role of utmost relevance, especially in the creation of symbols on the interface between the consciousness and the unconscious. Thus, the religious ground comes to provide a bridge, where the symbols are built and "resignified".

This book is based on the analysis of the mental historical facts which meet in an involuntary individual fantasy. This fantasy would be the "creating" fantasy which refers to the forgotten primitive spirit, backing into its peculiar images that are revealed in the mythologies of all times and of all people. For Jung (1912), the set of these images forms the collective unconscious, present in all individuals by heredity. These images are subject to reappear spontaneously everywhere. This fact justifies why the temporal and more distanced

Henrique Guilherme Scatolin, PUC-SP (Pontificate Catholic University of São Paulo). 
mythologem may belong to the same creator base: The human psyche, since the brain, despite the small variations, works everywhere in the same way.

This book exalts the case of Miss Miller, a patient who showed her unusual capacity for empathy and identification, although his examples of suggestibility were quite rich. While bringing the associations of Miller, Jung emphasizes the self-suggestibility effect, a moment when the libido has taken certain impressions and exaggerated it "due to the presence of the free energy 'available' as a result of an insufficient relationship with reality" (Jung, 1912, p. 59). The rich case of this patient showed the difficulty of a real affective relationship, leading it to strengthen her almost magical influence over another person, highlighting the suggestion strength present in her fantasies. This would exemplify the self-suggestibility, which action comes to exemplify how the libido has taken certain impressions and exaggerated it, thanks to the presence of the free energy available as a result of a bad relationship with reality.

Jung continues with this clinical case in item IV entitled The Hymn of Creation, bringing, early, the issue of "dementia praecox", i.e., schizophrenia. He frames a critique to the psychiatry of this time, although he highlights the consequences of reality introversion, a fact that manifested in the patient Miss Miller. He understands the schizophrenia as a mental disorder in which patients are increasingly closed against reality, submerging in their fantasies as the external reality weakness its influence and the inner world increases its authoritative strength.

Another important contribution is that Jung (1912) elaborates a conceptualization of the term imago. This would be the live independence in the psychic hierarchy, an autonomy "that crystallized as an essential particularity of the feelings complex at the expense of multiple experiences" (1912, p. 65). He also highlights that, throughout his work, he came to use the term archetype to treat the impersonal and collective reasons. For this author, archetype would be the structures where we find an innate predisposition for creating parallel fantasies, of "identical, universal structures of psyche" $(1912$, p. 190) and which he designated, afterwards, as collective unconscious.

It would be in this unconscious where the archetypes are present, where the patient is driven by instinct, due to his limitation or inhibition, to a possible regression, animating these archetypal structures.

Here there is an interesting data: Libido loses the sexual character conceived by Freud, becoming a driving force of the soul and which essence would yield "useful and harmful, good and bad things" (1912, p. 150). And why this new conception is so important to Jung? Because the creation of symbols is closely linked to the libido. For Jung, "We cannot treat the formation of symbols without including the instinctive processes, because from these come the driving force of the symbol" (1912, p. 273). Therefore, most of the symbols, to a greater or lesser extent, presents analogies of sexuality instinct, moment when the libido would fill the archetypes, "universally present and inherited forms that, in its totality, constitute the structure of the unconscious" (1912, p. 273). Thus, the archetypes are forms or beds into which the rivers of psychic phenomena would flow forever.

In addition, Jung (1912) understands that sexuality plays an important role in the formation of symbols, especially the religious. He points out how the first Christians would have distanced so strongly of their instincts, avoiding contact with their own sexuality, this would have provoked symbolic marks in Christianity, propitiating the formation of spiritual images. Thus, the symbols would offer paths for the libido, making them as bridges for the greatest achievements of humanity. These would have as a base the unconscious archetype, and which apparent image comes from the ideas that the conscious acquired. 
Jung considers the archetypes "as structural elements... of psyche" (1912, p. 277). It has autonomy and specific energy, in which the symbols would be its transformers, because they would lead to a lower sphere libido - of collective unconscious - to a higher form. The symbol would act in a suggestive manner, expressing the conviction contents. Jung mentions numerous symbols in this book, but I would like to mention a few:

The symbol of the tree: This is a maternal symbol, leading to religious myths;

The symbol of the serpent: This would have a phallic significance and in the religious myths, in contrast to orgy and the manifestation of sexuality, this would have a "religious connotation" (1912, p. 443). He points out that in the Ophites mysteries, the solemnity was celebrated with snakes and some animals were even kissed.

But how would the symbols transformations occur? For Jung (1912), the man is just transformed into what is already potentially inside him. Each transformation is unconsciously compensated by the archetype through another form of adaptation and signification, such as the cross can represent the removal of all misery, but also a symbol of rain and fertility. Thus, the cross is a symbol of many meanings, being one of its main meaning the life tree and the mother.

And so that the symbols break out, Jung (1912) mentions the regression. This would seek the path of libido so that the symbols break out as an expression, not allowing, in some cases, that libido stays stuck on maternal materiality. In every regression, libido can be diverted to a symbol or an equivalent symbolic of the father or the mother, in the collective unconscious. And, in addition to the regression, we would have the introversion of libido as another fundamental mechanism in the creation of symbols. So, it comes back to the serpent symbol.

For Jung, the unconscious can insinuate in the form of a serpent when the conscious fears the rewarding trend of the unconscious, which usually occurs in the regression; but who assumes an affirmative attitude towards the compensation does not regress and "will go" towards the unconscious through introversion (1912, p. 446). In many historical examples, it is through introversion that the individual is fertilized, delighted, re-generated and reborn.

Jung (1912) weaves another criticism to Freudian psychoanalysis, because in the "incest barrier" pointed by Freud there is a sexualist allegorizing. For Jung (1912), "Not everything is reduced to sexual pleasure, since "pleasure can be present in multiple sources" $(1912$, p. 487). He points out that the incest barrier "is a very dubious barrier (no matter how good it is for describing the neurotic states), since it represents a cultural acquisition that was not invented, but naturally originated, based on complicated biological needs that related to the appearance of the so-called marriage class systems" (1912, p. 487). These systems are not aimed at the prevention of incest, but rather the social danger of endogamy, a moment in which marriage would not prevent incest, very frequent in promiscuity attacks of primitives, but it would assume the need to extend the social organization to the entire tribe. It was not the incest taboo that removed the man from the indiscrimination state, but rather his "development instinct" and this imposed several taboos, differentiating him from other animals. In this context, he resumes that the neurosis, in his understanding, is not focused on the sexual theory and rather to the regression to the oral via, resplending the fear of being swallowed, denoting the act of being devoured. In this meander, the Oedipus complex is transformed into the Jonas-whale context, where the fear of incest becomes the fear of being eaten by the mother. The regression of libido is unsexed and, in the myth of Jonas and the whale, this regresses to the collective psyche where Jonas sees the mysteries, the collective representations, inside the whale belly. Therefore, the libido regression can animate collective images, the archetypes, which will have a rewarding and healing meaning, as the myth has always had. 
Jung points out that libido "in regression is hidden in numerous and quite variable symbols, regardless of male or female nature" (1912, p. 499). Libido can be an unstoppable impulse forward, in search of living and building; but it can also search its decline, its involution (a contradiction that is exemplified by the Verona statuette). So, the more the conscious denies the modification, the more the symbols will perpetuate in dreams and premonitions, becoming scary symbols. For example, the serpent, as a symbol of fear, can represent a precedence of physical illness, but the interpretation will depend on the individual circumstances of each patient.

In the epilogue, Jung brings the conclusion of Miss Miller case, since this case represents a clinic of unconscious manifestations. He points out that fantasies "come from a psychic energy not subject to the conscious control" (1912, p. 513). In these fantasies, we find impulses and symbolic events unrelated to the conscious. If the analyst explained the meaning of these fantasies to the patient, this would avoid the danger of his dissociations and which assimilation would avoid the isolation and, consequently, the psychosis.

It is in the gaps between the conscious and the unconscious that we can observe the neurosis and psychosis. In the individual with the tendency to neurosis, in this gap, we could find a neurotic state and in the individual with predisposition to psychosis, this gap could lead to isolation and schizophrenia, causing isolation and panic. The role of therapy, in both pathological frames, would lead to the integration of unconscious to consciousness contents, decreasing the dissociation. However, when the unconscious impulses are made instinctively, the spiritual contents are not taken into consideration. For this reason, the symbol comes to play a very important role, allowing the crossing between both sides. Therefore, the archetypal relations of unconscious products only occur with the collective representations, since the collective contents would be present in the transfer and are exalted in dreams, visions, fantasies and manias.

Summary concluded in the city of Brotas-SP, on January 17th, 2015.

\section{Bibliographical Reference}

Jung, C. G. (2011). Symbols of transformation: Preludes analysis of a schizophrenia (Translation of Eva Estern, 7th ed.). Petrópolis: Vozes. Original published in 1912. 